\title{
CHRONIC BRONCHITIS
}

\author{
By Neville Oswald, M.D., F.R.C.P. \\ Physician, St. Bartholomew's and Brompton Hospitals
}

The onset of chronic bronchitis may be acute, but is usually insidious. The first evidence of pulmonary involvement generally takes the form of a little cough and sputum for a few days following a cold in the head. This very minor occurrence seems in some way to sensitize the bronchi so that any subsequent cold may go down to the chest. The disability from the cough and sputum is negligible and a clinical diagnosis of bronchitis is not justified. Indeed, at least half of the general population have colds which at some time or other go down to the chest. Most patients affected in this way progress no further, but some find that over a period of years they reach the point at which the sputum persists for a week or two in each attack and starts to give some disability. This stage of recurrent bronchitis sometimes leads to fully developed chronic bronchitis, in which sputum is present throughout the winter months and, later, all the year round. At any stage in this process bronchospasm may be added, particularly during exacerbations of infection. The degree of accompanying emphysema depends more than anything else upon how far down the bronchial tree the infection has spread. Once it has reached the bronchioles and lobules, it causes permanent scarring, with consequent distension of the healthier parts of the lung.

In the later stages of chronic bronchitis, usually with bronchospasm and emphysema in addition, the combination of reduced effective alveolar surface and obstructed air flow lead to the serious and often fatal complications of bronchopneumonia, anoxia and heart failure.

This clinical description of the stages of chronic bronchitis and its complications clarifies to some extent the controversial problem of definition. Chronic bronchitis is best regarded as a chronic affection of the bronchi, having cough, sputum and breathlessness as its principal symptoms, which are likely to be worst during the winter months and are ordinarily aggravated by superimposed infection, air pollution and adverse climatic factors. There must be some disability either from exacerbations of infection or breathlessness or both, and the disability should have existed for at least two years not necessarily continuously.

The differentiation of chronic bronchitis from asthma and emphysema is not always easy. By British conventions, the term 'asthma' is ordinarily reserved for patients who have clear-cut attacks of bronchospasm associated with either personal or familial evidence of allergy, or with an eosinophilia in the blood or sputum. Emphysema, which is ordinarily a complication of chronic bronchitis, can apparently arise as a ' primary' disease, in which case it typically arises in adults between the ages of thirty and fifty and produces increasing breathlessness, which may be fatal within a couple of years.

In the present state of knowledge the causes of bronchitis are by no means obvious. The age of onset of symptoms is extremely variable. About I 5 per cent. of patients date the onset to the first decade of life, after which there is a decline in the teens, the remainder starting their symptoms more or less equally in each decade from the third onwards. Allergy follows roughly the same pattern in the younger age groups, but tends to diminish after the age of forty, at which time most bronchitics are beginning to become disabled. This suggests that allergy may contribute to bronchitis early in life, but that later on such factors as degenerative changes, recurrent infections and air pollution become dominant. Air pollution almost certainly contributes significantly to the onset of chronic bronchitis, although evidence completely satisfactory to statisticians is not yet forthcoming. However, both morbidity and mortality rates are almost twice as great in the industrial parts of Great Britain as in country districts. The vagaries of the English climate are not apparently responsible for the initiation of bronchitis by themselves, but they can cause considerable aggravation of symptoms once bronchitis has become established, especially if associated with air pollution.

Recent advances in the treatment of chronic bronchitis have resulted from special studies of specific aspects of the disease. Each patient needs 


\section{LLOYD-LUKE}

\section{Books that enshrine profound thought}

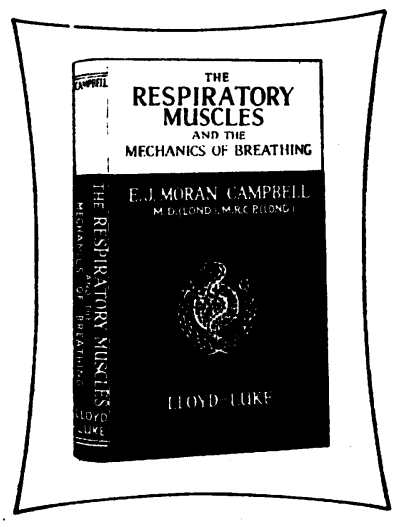

THE RESPIRATORY MUSCLES

E. J. Moran Campbell $x v i+132$ pp. 32 illus. Just published

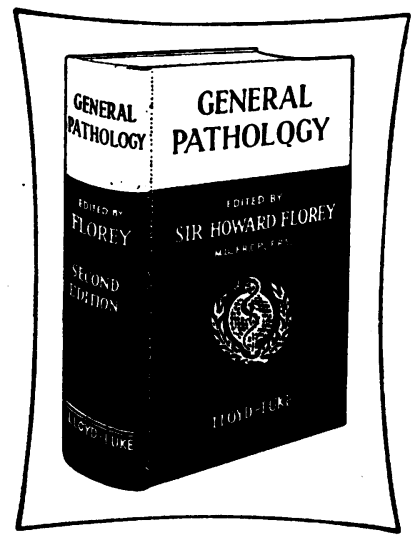

GENERAL PATHOLOGY (2nd edit.)

SIR HOWARD FLOREY $x v i+932$ pp. 410 illus. 3 colour plates Just published

$84 s$.

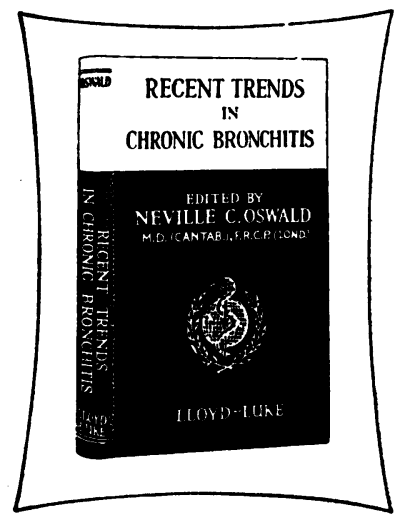

RECENT TRENDS IN CHRONIC BRONCHITIS NeVILLE C. OsWALD viii +200 pp. 76 illus. 2 colour plates

Just published 30 s.

\section{Lloyd-Luke (Medical Books) Ltd., 49, Newman Street, W.I}

to be assessed in terms of bronchial infection, mucus, bronchospasm and emphysema.

\section{Bronchial Infection}

Most bronchitics have a mucoid sputum during the summer months, which becomes purulent in the winter and during exacerbations. Although bacteria and viruses may play some part in the initiation of a mucoid sputum, no known antibiotic is capable of diminishing excessive mucus. Hence anti-bacterial therapy must only be administered when the sputum is purulent, or at the onset of an exacerbation of infection. The most important pathogenic bacteria are $H$. influenzae and the pneumococcus, particularly the former. When the pneumococcus is responsible it can easily be eradicated by a short course of penicillin and is unlikely to recur quickly. $H$. influenzae is much more difficult to eliminate, probably because it becomes firmly embedded in the bronchial walls. It responds to some extent to a combination of penicillin and streptomycin or, alternatively, to a tetracycline, but often re-appears when treatment is stopped. For an acute exacerbation 500,000 units of penicillin and $\frac{1}{2} \mathrm{~g}$. of streptomycin may be given intramuscularly twice a day for five days. These drugs produce a clinical effect within about
12 hours and should always be used when life is threatened. However, their administration is somewhat cumbersome and the streptomycin may cause vestibular disturbances in the elderly. Alternatively, $\frac{1}{2} \mathrm{~g}$. of tetracycline may be given three times a day for five days by mouth; this drug has the advantage of ease of administration, but usually does not have a clinical effect in under 48 hours and so should not be used in the seriously ill. Tetracycline is a useful drug for out-patients, who can take a few doses at the onset of an acute attack. In the ordinary way antibiotics should be reserved for acute exacerbations. Occasionally, however, patients are encountered who suffer from chronic ill health and who have a copious purulent sputum, particularly in the winter months. For these a course of long-term chemotherapy should be considered. Obviously an oral preparation is most desirable and sufficient tetracycline should be given to maintain a mucoid sputum. This varies from $\frac{1}{4}$ g. to $3 \mathrm{~g}$. of tetracycline a day. The general health of many such patients is greatly improved by, say, $\frac{1}{4}$ g. of tetracycline twice a day.

\section{Mucus}

As with the other features of chronic bronchitis, the most beneficial form of treatment is usually 
prophylaxis. This involves minimal exposure to infections, air pollution and adverse climatic factors. Medicinal measures designed to reduce excessive mucus are very disappointing. Inhalations of friars balsam, menthol and eucalyptus sometimes ease expectoration; aerosol trypsin, although expensive, reduces viscosity and often gives temporary relief. The effectiveness of the so-called expectorant mixtures must not be underestimated in long-term management.

\section{Bronchospasm}

This complication is very difficult to eradicate once it has become established. The greatest benefit is likely to be derived from prophylaxis. Ephedrine is a remarkably good drug for short periods, particularly if it is taken intermittently. Aminophylline is another favourite, but has the disadvantage that it is most likely to afford relief when given parenterally or by suppository. Steroids are uncertain in their effect and their action in individual patients can only be determined by trial and error. Often a dose of 5 to ro $\mathrm{mg}$. of prednisone a day for a few weeks will tide a patient over a bad spell, but larger doses should be avoided if possible and long courses are undesirable.

\section{Emphysema}

In clinical terms, this is a disease of reduced effective alveolar surface and obstructed air flow. The best that treatment can offer is to counteract these mechanical disadvantages. For this purpose special breathing exercises have been devised which aim to reduce muscular rigidity, increase skeletal suppleness and to promote controlled respiration. Untreated emphysematous patients usually rely to a large extent upon the muscles of their neck and the upper intercostal muscles for respiration. The exercises encourage lateral expansion of the lower ribs and diaphragmatic breathing, thus allowing patients to maintain their tidal air with much less effort. Most of these patients are benefited by these exercises, and some to a remarkable degree.

\section{Conclusion}

In conclusion, chronic bronchitis offers a formidable medical problem. It is responsible for roughly 7 per cent. of all deaths in Britain and 7 per cent. of sickness absence from all causes. Undoubtedly infection and air pollution contribute to its development. If these could be reduced, less attention would need to be paid to the rather ineffective curative measures at present available.

\title{
HOW TO GET THERE
}

An Address Book for the Medical profession, showing how to reach the various Colleges, Societies, Institutes and Hospitals in or near London

New (Fourth) Edition: 1954

Price 2s. 6d. (2s. 10d., post free)

Published by the

\section{FELLOWSHIP OF POSTGRADUATE MEDICINE}

\author{
60 Portland Place, London, W.I
}

Bibliography continued from page 10-Asthma, by Bruce Pearson, D.M., F.R.C.P.

DEKKER, E., PELSER, H. E., and GROEN, J. (1957), $\mathcal{f}$. psychosom. Res., 2, 97.

FEINBERG, S. M. (1944), 'Allergy in Practice,' Chicago Year Book Publications.

FLENSBORG, E. W. (1945), Acta paediat. (Uppsala), 33, 4.

FLOYER, SIR JOHN (1717), 'A Treatise of the Asthma,' London.

GEAR, J.' (1955), Acta med. scand., supp., 306, 39.

GRANT, G. (1957), Acta allerg. (Kbh.), i 1, 37 .

KALLOS, P. (1953), Int. Arch. Allergy, 4, 291.

LEIGH, DENIS, and RAWNSLEY, K. (1956), Ibid., 9, 305.

LEIGH, DENIS, and MARLEY, E. (1956), ' F. psychosom. Res.,

LEIGH, DENIS (1953), Int. Arch. Allergy, \& 227.
MILLER, HYMAN, and BARUCH, DOROTHY W. (I956), 'Practice of Psychosomatic Medicine,' London. RACKEMANN, F. M., and EDWARDS, M. C. (1952), New Engl. F. Med., 246, 8 i 5,858 .

REES, LINFORD (I956), F. psychosom. Res., I, 98.

SALTER, A. HYDE (I860), 'Asthma,' London.

SCHWARTZ, M. (1952), Acta Allerg. (Kbh.), supp. 2.

VALLERY RADOT, P., HALPERN, B. M., BLAMOUTIER, P., BIOZZI, G., BENARORRAF, B. (1956), 'Relazione e Com-' municazione, 'Third European Congress of Allergy,' $\mathbf{I}, 5$.

WILLIAMS, D. A., 'First International Congress for Allergy,' p. 42, Basel. 